\title{
A INTRODUÇÃO DA PENICILINA NOS HOSPITAIS DA UNIVERSIDADE DE COIMBRA, PORTUGAL (1944-1946) ${ }^{1}$
}

\author{
Victoria Bell \\ University of Coimbra, CEIS20-Faculty of Pharmacy \\ victoriabell@ff.uc.pt \\ Ana Leonor Pereira \\ University of Coimbra, CEIS20-Faculty of Arts and Humanities (Dep. History) \\ aleop@ci.uc.pt \\ João Rui Pita \\ University of Coimbra, CEIS20-Faculty of Pharmacy \\ jrpita@ci.uc.pt
}

Recibido: 4 septiembre 2014; Aceptado: 20 junio 2015.

Cómo citar este artículo/Citation: Bell, Victoria; Ana Leonor Pereira y João Rui Pita (2016), "A introdução da penicilina nos hospitais da Universidade de Coimbra, Portugal (1944-1946)", Asclepio 68 (1): p137 .doi: http://dx.doi.org/10.3989/asclepio.2016.16

RESUMO: A importação regular de penicilina para Portugal iniciou-se em Setembro de 1944 através da Cruz Vermelha Portuguesa. Até Junho de 1945 a importação e distribuição do medicamento foram controladas por esta instituição humanitária mas a partir desta data, com o aumento da produção mundial, a penicilina começou a ser importada por intermédio da indústria farmacêutica. No Arquivo da Universidade de Coimbra consultamos papeletas (processos individuais) de doentes internados nos Hospitais da Universidade de Coimbra desde Setembro de 1944 até Agosto de 1946. A investigação realizada permitiu-nos recolher informações sobre a introdução da penicilina e sobre os primeiros tratamentos efetuados com o medicamento nestes hospitais. Com base nos dados recolhidos pretendemos, pelo presente artigo, mostrar como foi feita a receção da penicilina num hospital central de grande dimensão, um dos principais hospitais portugueses, saber a frequência com que era prescrita, as patologias mais comuns em que era empregue, as doses administradas, a posologia e o tempo de tratamento assim como os clínicos responsáveis pela sua prescrição.

PALAVRAS-CHAVE: Penicilina; Hospitais da Universidade de Coimbra; Terapêutica; Medicamento; Século XX (1944-1946).

\section{THE INTRODUCTION OF PENICILLIN IN COIMBRA UNIVERSITY HOSPITALS, PORTUGAL (1944-1946)}

ABSTRACT: The Portuguese Red Cross began to import of penicillin regularly following September 1944. Until June 1945, the humanitarian institution controlled the distribution of the antibiotic, subsequently, due to the increase in world production penicillin began to be imported by means of the pharmaceutical industry. We consulted and analyzed files of patients admitted to Coimbra University Hospitals between September 1944 and August 1946. These files, located in Coimbra University Archive, enabled us to collect information on the introduction of penicillin and on the first cases treated with the antibiotic at these hospitals. In the present paper, we aim to shed some light upon how penicillin was received in one of the main Portuguese central hospitals, the frequency with which it was prescribed, the most common diseases in which the antibiotic was utilized, the dosage administrated, the length of the treatment and the physicians responsible for prescribing the antibiotic.

KEY WORDS: Penicillin; Coimbra University Hospitals; Therapeutics; Medicines; Twentieth Century (1944-1946)

Copyright: () 2016 CSIC. Este es un artículo de acceso abierto distribuido bajo los términos de la licencia Creative Commons Attribution (CC BY) España 3.0. 


\section{INTRODUÇÃO}

A descoberta da penicilina e a sua introdução na terapêutica veio alterar por completo o prognóstico do tratamento das doenças infeciosas (Queijo, 2010) modificando o percurso da medicina e salvando inúmeras vidas (Waller, 2004). Foi uma das descobertas científicas mais mediáticas da história da medicina e constituiu o ponto de partida para a investigação de novos antibióticos (Lesch, 2007)2. Têm sido realizados vários estudos sobre a receção da penicilina em diversos países precisamente pela importância que o antibiótico teve na inovação terapêutica, na clínica médica, na industrialização do medicamento e ainda na comercialização do mesmo ${ }^{3}$.

Em Portugal, mesmo antes de ser utilizado, o medicamento era visto como «a última tentativa de salvação " ${ }^{4}$ para doentes que se encontravam em perigo de vida pela gravidade da sua enfermidade.

A penicilina começou a ser importada com regularidade para Portugal ${ }^{5}$ a partir de Setembro de 1944. A Cruz Vermelha Portuguesa (CVP) foi a entidade responsável pela importação e distribuição do medicamento até Junho de 1945, durante este período as quantidades de fármaco disponíveis eram limitadas obrigando à constituição de uma comissão controladora ${ }^{6}$ para analisar os pedidos de penicilina que diariamente chegavam à CVP7. Esta comissão - Junta Consultiva da Cruz Vermelha Portuguesa para a Distribuição da Penicilina em Portugal ${ }^{8}$ (JCDPP) - constituída por ilustres clínicos da época Prof. Doutor Francisco Gentil (presidente)", Doutor Luís António Xavier Júnior (secretário), Prof. Doutor Fernando da Fonseca ${ }^{10}$, Prof. Doutor João Maia Loureiro ${ }^{11}$ e Doutor Ernesto Galeão Roma ${ }^{12}$ (como vogais) foi responsável por organizar a distribuição de penicilina no nosso país. Foi criado um impresso próprio para a requisição do medicamento e implementados rigorosos procedimentos de modo a que as escassas quantidades de penicilina existentes fossem utilizadas racionalmente. Com o aumento da produção mundial de penicilina deixou de ser necessário controlar a sua distribuição ${ }^{13}$. A partir de Junho de 1945 o medicamento começou a ser importado e distribuído através da indústria farmacêutica, como os demais medicamentos e a ser vendido nas farmácias portuguesas como medicamento de prescrição médica obrigatória (Anónimo, 1945). Os primeiros laboratórios importadores e distribuidores foram o Instituto Pasteur de Lisboa, a Farmácia Barral e o Laboratório Sanitas com delegações em Lisboa, Porto e Coimbra e a Sociedade Industrial Farmacêutica e Santos Mendonça Ld.a em Lisboa.
A investigação conduzida no Arquivo da Universidade de Coimbra permitiu-nos recolher informações sobre a introdução da penicilina nos Hospitais da Universidade de Coimbra (HUC) ${ }^{14}$ e sobre os primeiros tratamentos efetuados com o medicamento nestes hospitais. No Arquivo da Universidade de Coimbra consultamos papeletas de doentes internados nos Hospitais da Universidade desde Setembro de 1944 a Agosto de $1946^{15}$. Foi escolhida esta cronologia por compreender um período de aproximadamente doze meses (entre Setembro de 1944 e Junho de 1945) em que a distribuição da penicilina se encontrava sobre o controlo da Cruz Vermelha Portuguesa e um período idêntico em que a importação do medicamento foi efetuada através da indústria farmacêutica nacional. Nesta investigação propusemo-nos conhecer a receção da penicilina num hospital central, saber a frequência com que era prescrita, as patologias mais comuns em que era empregue, as doses administradas, a posologia e o tempo de tratamento assim como os clínicos responsáveis pela sua prescrição.

\section{FONTES DE INFORMAÇÃO CLÍNICA NOS HOSPITAIS DA UNIVERSIDADE DE COIMBRA (1944-1946)}

As papeletas dos doentes internados nos Hospitais da Universidade de Coimbra encontram-se no Fundo Universitário, 3a Secção, 4o Piso do Arquivo da Universidade de Coimbra ${ }^{16}$, estando arquivadas em caixas organizadas por data de alta dos doentes. A nossa investigação iniciou-se em Setembro de 1944 (caixa número 254) e terminou em Agosto de 1946 (caixa número 277), tendo sido consultadas 20896 (vinte mil oitocentas e noventa e seis) papeletas. Visto pretendermos apurar informações sobre a utilização de penicilina nos Hospitais da Universidade as papeletas consultadas foram subdivididas em duas categorias, a primeira onde se encontram os doentes tratados com penicilina ou com sulfamidas e uma segunda onde incluímos os restantes. Nas papeletas dos doentes que não receberam tratamento com penicilina ou sulfamidas ${ }^{17}$ recolhemos informações respeitantes ao género, data de admissão, data de alta e resultado do internamento. Nos doentes em que aqueles fármacos foram administrados recolhemos além destas informações dados sobre a localidade de residência, idade, profissão, diagnóstico da doença, dose e posologia administrada, tratamento cirúrgico efetuado, clínico prescritor e o resultado do internamento. Das 20896 papeletas consultadas 18227 eram referentes a doentes a quem não fora administrada penicilina e/ou sulfamidas, 2669 concernentes a doentes tratados com estes medicamentos e destas 670 referiam-se a doentes aos quais foi prescrita penicilina. 
Fizemos também um cruzamento dos dados recoIhidos no Arquivo da CVP com os dados das papeletas existentes no Arquivo da Universidade de Coimbra. Apurámos que nos Hospitais da Universidade de Coimbra foi administrada penicilina a 40 doentes até Julho de 1945 e que a CVP enviou para estes hospitais penicilina para o tratamento de 43 doentes, 41 das requisições existentes no Arquivo da CVP mencionam o doente para o qual o medicamento foi enviado e as 2 restantes referem somente que a penicilina foi enviada para os Hospitais da Universidade de Coimbra ou para o seu Diretor, o Dr. João Porto. Supomos que a penicilina referente a uma destas requisições, sem identificação, foi destinada a um doente internado na Clínica Psiquiátrica da Faculdade de Medicina de Coimbra. O doente foi tratado pelo Dr. Rui Clímaco em Dezembro de 1944 e o resultado das suas observações foi publicado, em 1946, na revista A Medicina Contemporânea no artigo «Revisão clínica das psicoses infeciosas e pós infeciosas» (Clímaco, 1946). Neste trabalho o autor refere a administração de penicilina, com sucesso, num caso de confusão mental alucinogénica provocado por uma septicémia estafilocócica. 0 doente foi internado na Clínica Psiquiátrica da Faculdade de Medicina de Coimbra em Novembro de 1944. O autor descreve pormenorizadamente a história clínica do doente, os exames efetuados, a terapêutica instituída e a evolução da sintomatologia. No tratamento com penicilina, Rui Clímaco refere as doses administradas, a frequência da administração e a dose total empregue (500 000 unidades), menciona as dificuldades encontradas na obtenção do medicamento e que estas só foram resolvidas, a 9 de Dezembro de 1944, após a intervenção do Diretor dos Hospitais da Universidade de Coimbra junto da Cruz Vermelha Portuguesa. Após a discussão do caso clínico o autor faz uma revisão da bibliografia sobre psicoses infeciosas e pós-infeciosas, no capítulo onde aborda a terapêutica da infeção expõe as vantagens da utilização da penicilina em detrimento das sulfamidas. Relativamente ao caso clínico que apresentou Rui Clímaco mostrou-se surpreso com a ação do medicamento, afirmando que «muito embora estivéssemos convencidos de que a dose de penicilina empregada era insuficiente, ficámos altamente surpreendidos ao verificar que os abcessos múltiplos tinham sido absorvidos sem deixar quaisquer vestígios» (Clímaco, 1946). No Arquivo da Cruz vermelha Portuguesa encontrámos registo de uma requisição de penicilina pelo Diretor dos Hospitais da Universidade de Coimbra, Dr. João Porto, em 5 de Dezembro de $1944^{18} \mathrm{e}$ a confirmação da receção de cinco ampolas de penicilina pelo mesmo em 8 de Dezembro de $1944^{19}$. Não podemos garantir que estas ampolas de penicilina terão sido as empregues por Rui Clímaco no tratamento do doente mencionado no seu artigo mas a coincidência de datas e na quantidade de penicilina administrada leva-nos a supor que se tratam das mesmas.

Dos 40 doentes tratados com penicilina nos Hospitais da Universidade de Coimbra, até Julho de 1945, encontrámos em 29 uma correspondência exata nas requisições existentes no Arquivo da Cruz Vermelha Portuguesa.

As papeletas dos Hospitais da Universidade de Coimbra ${ }^{20}$ são boletins com formato $\mathrm{A} 3$ dobrados em três partes e com informação em ambos os lados. Contêm uma seção administrativa, "A - Parte Administrativa» e uma seção clínica, «B - Parte Clínica». Na frente da papeleta encontra-se a "Parte Administrativa», subdividida em três seções, "I - Registo da Entrada», "II - Registo da Saída» e no verso «III - Registo de objetos trazidos pelo doente». A "Parte Clínica» engloba também três seções, «I - Registo Clínico da Saída», «ll -Registo Clínico de Estada» e «III - Registo Clínico da Admissão». Entre a seção administrativa e a clínica existe local destinado a registar as transferências de enfermaria e de hospital efetuadas pelo doente. O campo «I - Registo da Entrada» destina-se a recolher os dados do doente (nome, filiação, idade, estado civil, profissão, naturalidade e residência), a registar a data de admissão e o número do livro e do boletim correspondentes à mesma. O «ll - Registo da Saída» refere a data da alta ou do falecimento do doente. No setor «III - Registo de Objetos Trazidos pelo Doente» existe, além do campo destinado a registar aqueles objetos, um outro para recolha de «Informações para o Instituto Nacional de Estatística». Na primeira seção da "Parte Clínica», «I - Registo Clínico da Saída», são recolhidos dados referentes ao "Diagnóstico», "Tratamento» e "Resultado», na seção «ll - Registo Clínico de Estada» consta a «Enfermaria» e o «№ de Cama» do doente assim como o "Diário» de internamento onde devem ser registadas as "Prescrições», as «Dietas» e as «Datas» em que foram instituídas. Na seção «III - Registo da Admissão» o clínico deveria mencionar a seção e a enfermaria para onde doente seria admitido, se a admissão era «Urgente», se estava aconselhado o "Banho Geral», qual o "Tratamento Clínico» prescrito e no campo «Observações» habitualmente era efetuado o registado do diagnóstico efetuado.

As papeletas constituem uma importante fonte de informação sobre os doentes internados nos Hospitais da Universidade de Coimbra, no entanto, o seu preenchimento nem sempre foi completo o que dificultou a nossa recolha de dados. A constatação deste facto vai ao encontro das declarações proferidas pelo Prof. Doutor Cid dos Santos, em 1954, na Assembleia Nacional 
onde refere que «entre nós não existe qualquer tradição de arquivos clínicos ... nada obriga a registar as histórias dos doentes e a sua evolução» (Santos, 1954). Na maioria das papeletas consultadas a "Parte Clínica» não contem informações sobre a posologia e tempo de tratamento e o nome do clínico prescritor nem sempre é percetível. Com base nos elementos disponíveis fizemos um tratamento de dados o mais completo possível.

\section{CARACTERIZAÇÃO GERAL DOS PRIMEIROS TRATA- MENTOS COM PENICILINA NOS HOSPITAIS DA UNI- VERSIDADE DE COIMBRA (1944-1946)}

O primeiro doente, que encontrámos, a quem foi administrada penicilina nos Hospitais da Universidade de Coimbra foi uma mulher de 25 anos, solteira, doméstica, residente em Porto de Mós, no distrito de Leiria, admitida em 4 de Novembro de 1944. O registo clínico da admissão refere que a doente foi admitida com caracter urgente para a seção de cirurgia, foi observada pelo Dr. Trajano Pinheiro que lhe diagnosticou uma «artrite aguda do joeIho esquerdo» tendo-lhe prescrito, para administração na enfermaria, sulfamidas, 1 comprimido de 4 em 4 horas, cataplasmas, 5 centímetros cúbicos de óleo canforado e colargol. Na seção da papeleta «I - Registo Clínico da Saída» surge como doença principal diagnosticada uma "septicémia» e como tratamento prescrito "penicilina», «transfusão de sangue» e «sulfamidas». Na seção «ll - Registo Clínico de Estada» verificamos que foi efetuada uma transfusão de sangue no dia 16 de Novembro de 1944, foram administradas 3 ampolas de cibazol ${ }^{21}, 3$ ampolas de coramina e 20 comprimidos de cibazol, não está registada a data nem o modo de administração. Relativamente à penicilina não consta qualquer informação sobre a posologia, o modo como foi administrada nem sobre a duração do tratamento. A doente viria a falecer no dia 29 de Novembro de 1944 após 25 dias de internamento ${ }^{22}$.

Tabela 1. Distribuição dos doentes em função do género*

\begin{tabular}{lcccc}
\hline Sexo & $\begin{array}{c}\text { No Total } \\
\text { Doentes } \\
\text { Admitidos }\end{array}$ & $\begin{array}{c}\text { No Doentes } \\
\text { Tratados com } \\
\text { Penicilina }\end{array}$ & $\%$ \\
\hline Homens & 10189 & $49 \%$ & 382 & $57 \%$ \\
\hline Total & 20896 & $100 \%$ & 670 & $100 \%$ \\
\hline
\end{tabular}

* Dados retirados de papeletas de doentes internados nos Hospitais da Universidade de Coimbra. As papeletas encontram-se no Arquivo da Universidade de Coimbra, 4으 Piso, 3a Secção, Fundo Universitário. Foram consultadas as caixas no 254 - no 277 , referentes a doentes internados nos Hospitais da Universidade de Coimbra e a quem foi dada alta entre Setembro de 1944 a final de Agosto de 1946.
A Tabela 1 representa a distribuição dos doentes de acordo com o género, constamos que do total de 20896 doentes admitidos, 51\% eram mulheres e $49 \%$ homens, relativamente aos doentes aos quais foi administrada penicilina verificamos que o medicamento foi mais prescrito em doentes do sexo masculino, $57 \%$, que em doentes do sexo feminino, $43 \%$. As maiores discrepâncias encontradas foram no tratamento de "úlceras» em que registámos 26 casos de utilização de penicilina em doentes do sexo masculino e dois no tratamento de doentes do sexo feminino; no tratamento de "fraturas», 22 doentes do sexo masculino e 3 do sexo feminino; no tratamento de "patologias respiratórias», 68 doentes do sexo masculino e 38 doentes do sexo feminino. Nos casos diagnosticados com «septicémia» registámos um maior equilíbrio entre os doentes do sexo masculino tratados com o antibiótico (20 casos) e os doentes do sexo feminino (14 casos); o mesmo se verificou nos casos diagnosticados com "osteomielite» em que registámos 30 doentes do sexo masculino tratados com penicilina e 23 doentes do sexo feminino e nos casos diagnosticados com "fleimão», 22 doentes do sexo masculino e 16 doentes do sexo feminino. Nas patologias "ginecológicas» foram somente tratadas doentes do sexo feminino. $\mathrm{Na}$ Tabela 7 encontram-se discriminadas as principais patologias em que a penicilina foi empregue.

A Tabela 2 refere-se à distribuição de doentes em função da data em que lhes foi dada alta. Podemos observar que entre Setembro de 1944 e Agosto de 1946 o número mensal de altas de internamento foi relativamente constante, no entanto, quando analisamos a coluna referente aos doentes aos quais foi administrada penicilina verificamos que até Julho de 1945 o número mensal de altas de internamento foi muito baixa, fato congruente com a dificuldade existente na obtenção de penicilina e no seu elevado custo $^{23}$, a partir de Agosto de 1945 o número mensal de altas de internamento de doentes aos quais foi administrado o antibiótico aumentou progressivamente até atingir e em alguns meses ultrapassar metade do número mensal de altas de internamento de doentes aos quais foi prescrita outra medicação (sulfamidas) para o tratamento de patologias infeciosas, este fato também é concordante com a existência de maiores quantidades de penicilina disponíveis e com a diminuição do seu custo ${ }^{24}$. Através dos dados expostos nesta tabela constatamos que os Hospitais da Universidade de Coimbra começaram a utilizar penicilina nos seus serviços a partir de Novembro de 1944 e que, apesar das dificuldades existentes na obtenção e distribuição, o antibiótico foi bem aceite e rapidamente 
integrado na medicação habitualmente prescrita para o tratamento de patologias infeciosas nestes hospitais. Quando o medicamento deixou de estar sobre o controlo da Cruz Vermelha Portuguesa e passou a estar disponível nos canais habituais de distribuição de medicamentos (Anónimo, 1945), importação através da indústria farmacêutica e venda em farmácias ${ }^{25}$, verificámos através de dados consultados nas papeletas dos Hospitais da Universidade de Coimbra que houve um incremento significativo da prescrição do antibiótico naqueles serviços hospitalares.
Por observação da Tabela 3 verificamos que a penicilina foi prescrita por clínicos de diversas especialidades médicas (Boletim dos Hospitais da Universidade de Coimbra, 1947). Na especialidade de ginecologia e obstetrícia surgem Ibérico Nogueira, Luís Raposo e Bissaya Barreto, em oftalmologia Cunha Vaz, urologia Morais Zamith e em cirurgia Nunes da Costa. Como já havíamos referido o preenchimento das papeletas nem sempre era completo o que impossibilitou a recolha de mais informação sobre os clínicos que prescreveram penicilina durante o período que nos pro-

Tabela 2. Distribuição dos doentes de acordo com a data de alta ( $\mathrm{n}$ - total de doentes, $\mathrm{n}$ - de doentes tratados com penicilina e/ou sulfamidas e $\mathrm{n}$ - de doentes tratados com penicilina)*

\begin{tabular}{|c|c|c|c|c|c|c|}
\hline Mês & Ano & Total & Sul/Pen & Penicilina & $\%$ Total Altas & $\%$ Tratamentos Sul/Pen \\
\hline Setembro & 1944 & 793 & 66 & 0 & $0,0 \%$ & $0,0 \%$ \\
\hline Outubro & 1944 & 908 & 65 & 0 & $0,0 \%$ & $0,0 \%$ \\
\hline Novembro & 1944 & 854 & 66 & 1 & $0,1 \%$ & $1,5 \%$ \\
\hline Dezembro & 1944 & 804 & 102 & 1 & $0,1 \%$ & $1,0 \%$ \\
\hline Janeiro & 1945 & 798 & 123 & 7 & $0,9 \%$ & $5,7 \%$ \\
\hline Fevereiro & 1945 & 788 & 142 & 2 & $0,3 \%$ & $1,4 \%$ \\
\hline Março & 1945 & 883 & 112 & 2 & $0,2 \%$ & $1,8 \%$ \\
\hline Abril & 1945 & 784 & 137 & 0 & $0,0 \%$ & $0,0 \%$ \\
\hline Maio & 1945 & 913 & 178 & 4 & $0,4 \%$ & $2,2 \%$ \\
\hline Junho & 1945 & 870 & 135 & 11 & $1,3 \%$ & $8,1 \%$ \\
\hline Julho & 1945 & 943 & 151 & 12 & $1,3 \%$ & $7,9 \%$ \\
\hline Agosto & 1945 & 863 & 106 & 19 & $2,2 \%$ & $17,9 \%$ \\
\hline Setembro & 1945 & 821 & 93 & 19 & $2,3 \%$ & $20,4 \%$ \\
\hline Outubro & 1945 & 1005 & 122 & 48 & $4,8 \%$ & $39,3 \%$ \\
\hline Novembro & 1945 & 911 & 132 & 55 & $6,0 \%$ & $41,7 \%$ \\
\hline Dezembro & 1945 & 905 & 117 & 51 & $5,6 \%$ & $43,6 \%$ \\
\hline Janeiro & 1946 & 784 & 95 & 37 & $4,7 \%$ & $38,9 \%$ \\
\hline Fevereiro & 1946 & 830 & 118 & 51 & $6,1 \%$ & $43,2 \%$ \\
\hline Março & 1946 & 892 & 116 & 69 & $7,7 \%$ & $59,5 \%$ \\
\hline Abril & 1946 & 910 & 108 & 49 & $5,4 \%$ & $45,4 \%$ \\
\hline Maio & 1946 & 856 & 97 & 54 & $6,3 \%$ & $55,7 \%$ \\
\hline Junho & 1946 & 938 & 91 & 51 & $5,4 \%$ & $56,0 \%$ \\
\hline Julho & 1946 & 938 & 103 & 58 & $6,2 \%$ & $56,3 \%$ \\
\hline Agosto & 1946 & 907 & 96 & 69 & $7,6 \%$ & $71,9 \%$ \\
\hline Total & & 20898 & 2671 & 670 & & \\
\hline \multicolumn{3}{|c|}{ \% Em relação ao total de altas } & $12,78 \%$ & $3,21 \%$ & & \\
\hline \multicolumn{4}{|c|}{ \% Em relação aos tratamentos com sul/pen } & $25,08 \%$ & & \\
\hline
\end{tabular}

* Dados retirados de papeletas de doentes internados nos Hospitais da Universidade de Coimbra. As papeletas encontram-se no Arquivo da Universidade de Coimbra, 4으 Piso, 3a Secção, Fundo Universitário. Foram consultadas as caixas no $254-$ nำ 277, referentes a doentes internados nos Hospitais da Universidade de Coimbra e a quem foi dada alta entre Setembro de 1944 a final de Agosto de 1946. 
Tabela 3. Distribuição dos doentes de acordo com o médico prescritor*

\begin{tabular}{|c|c|c|}
\hline Médico & Número de doentes & $\%$ \\
\hline Abílio de Andrade & 11 & $1,6 \%$ \\
\hline Albertino de Barros (clínica obstétrica) & 15 & $2,2 \%$ \\
\hline Alexandre da Silva (clínica cirúrgica; laringologia) (clínica ginecológica) & 7 & $1,0 \%$ \\
\hline António de Matos Beja (clínica ginecológica) & 1 & $0,1 \%$ \\
\hline António Taborda & 1 & $0,1 \%$ \\
\hline Bissaya Barreto (clínica cirúrgica e ortopedia) & 29 & $4,3 \%$ \\
\hline Borges do Nascimento (clínica cirúrgica) & 3 & $0,4 \%$ \\
\hline Brito Amaral & 5 & $0,7 \%$ \\
\hline Cunha Vaz (oftalmologia) & 6 & $0,9 \%$ \\
\hline Dinis Vieira (clínica cirúrgica e ortopedia) & 5 & $0,7 \%$ \\
\hline Fausto Pimentel (clínica cirúrgica) & 28 & $4,2 \%$ \\
\hline Fernando de Oliveira (clínica cirúrgica; laringologia) (clínica ginecológica) & 2 & $0,3 \%$ \\
\hline Francisco Pimentel (clínica cirúrgica; laringologia) & 2 & $0,3 \%$ \\
\hline Ibérico Nogueira (clínica obstétrica) & 5 & $0,7 \%$ \\
\hline João Pinheiro & 4 & $0,6 \%$ \\
\hline João Porto (medicina interna) & 1 & $0,1 \%$ \\
\hline Joaquim Gonçalves & 2 & $0,3 \%$ \\
\hline José Bacalhau (clínica cirúrgica) & 2 & $0,3 \%$ \\
\hline José Oliveira (clínica cirúrgica) & 3 & $0,4 \%$ \\
\hline Luís Raposo (clínica ginecológica) & 19 & $2,8 \%$ \\
\hline Manuel Montezuma & 6 & $0,9 \%$ \\
\hline Mário Carneiro (clínica cirúrgica) & 15 & $2,2 \%$ \\
\hline Morais Zamith (clínica urológica) & 7 & $1,0 \%$ \\
\hline Mota & 1 & $0,1 \%$ \\
\hline Novais e Sousa (clínica obstétrica) & 1 & $0,1 \%$ \\
\hline Nunes da Costa (clínica cirúrgica) & 42 & $6,3 \%$ \\
\hline Palmiro Baptista (clínica obstétrica) & 5 & $0,7 \%$ \\
\hline Penha (clínica cirúrgica; laringologia) & 4 & $0,6 \%$ \\
\hline Ramos Lopes & 3 & $0,4 \%$ \\
\hline Rodrigo Santiago & 1 & $0,1 \%$ \\
\hline Sena de Oliveira (clínica cirúrgica; laringologia) & 1 & $0,1 \%$ \\
\hline Trajano Pinheiro (clínica cirúrgica e ortopedia) & 21 & $3,1 \%$ \\
\hline Um aluno & 1 & $0,1 \%$ \\
\hline Vieira & 2 & $0,3 \%$ \\
\hline Sem médico/ilegível & 409 & $61,0 \%$ \\
\hline Total & 670 & $100,0 \%$ \\
\hline
\end{tabular}

* Dados retirados de papeletas de doentes internados nos Hospitais da Universidade de Coimbra. As papeletas encontram-se no Arquivo da Universidade de Coimbra, 40 Piso, 3a Secção, Fundo Universitário. Foram consultadas as caixas no 254 - oㅡ 277, referentes a doentes internados nos Hospitais da Universidade de Coimbra e a quem foi dada alta entre Setembro de 1944 a final de Agosto de 1946. 
pusemos estudar. Por análise da Tabela 3 podemos observar que surgem, como prescritores de penicilina, alguns nomes sonantes da medicina portuguesa como Fernando Baeta Bissaya Barreto Rosa (1886$1974)^{26}$, Luís Augusto de Morais Zamith (1897-1983) ${ }^{27}$ e João Maria Porto (1891-1968) ${ }^{28}$.

A localidade de residência dos doentes ${ }^{29}$ foi outro parâmetro que analisámos, em conformidade com o esperado a grande maioria dos doentes admitidos nos Hospitais da Universidade de Coimbra tratados com penicilina residia no distrito de Coimbra, também verificamos que existe uma percentagem relativamente elevada de doentes residentes nos distritos de Leiria, Guarda, Viseu e Aveiro, as localidades menos representativas são Beja, Bombarral e Porto.

Tabela 4. Distribuição dos doentes de acordo com a localidade de residência*

\begin{tabular}{lcc}
\hline Localidade & No de doentes & $\%$ \\
\hline Aveiro & 32 & $4,8 \%$ \\
\hline Beja & 1 & $0,1 \%$ \\
\hline Bombarral & 1 & $0,1 \%$ \\
\hline Bragança & 4 & $0,6 \%$ \\
\hline Castelo Branco & 12 & $1,8 \%$ \\
\hline Coimbra & 341 & $50,9 \%$ \\
\hline Figueira da Foz & 34 & $5,1 \%$ \\
\hline Guarda & 44 & $6,6 \%$ \\
\hline Leiria & 98 & $14,6 \%$ \\
\hline Portalegre & 8 & $1,2 \%$ \\
\hline Porto & 1 & $0,1 \%$ \\
\hline Santarém & 23 & $3,4 \%$ \\
\hline Viana do Castelo & 6 & $0,9 \%$ \\
\hline Vila Real & 8 & $1,2 \%$ \\
\hline Viseu & 57 & $8,5 \%$ \\
\hline Total & 670 & $100,0 \%$ \\
\hline
\end{tabular}

* Dados retirados de papeletas de doentes internados nos Hospitais da Universidade de Coimbra. As papeletas encontram-se no Arquivo da Universidade de Coimbra, 4우 Piso, 3a Secção, Fundo Universitário. Foram consultadas as caixas no 254 - no 277 , referentes a doentes internados nos Hospitais da Universidade de Coimbra e a quem foi dada alta entre Setembro de 1944 a final de Agosto de 1946.

O resultado do tratamento dos doentes aos quais foi administrada penicilina pode ser analisado através dos dados expostos na Tabela 5, verificamos que a maioria, $78,66 \%$, dos doentes tratados com penicilina se encontravam curados quando obtiveram alta e que $12,69 \%$ faleceram. Os dados observados encontram-se em consonância com os resultados descritos por autores americanos e britânicos, que registaram, respetivamente, uma percentagem de cura de $73,2 \%$ e $71,5 \%$ (Florey, 1944). Nos Hospitais da Universidade de Coimbra, em 1941, a percentagem de cura de doentes diagnosticados com "septicémia» foi de $42,9 \%$ e diagnosticados com «broncopneumonia» foi de 43,8\% (Anónimo, 1947). Com a introdução da penicilina naqueles serviços, e de acordo com os dados recolhidos, a percentagem de cura para as referidas patologias aumentou substancialmente, passando a situar-se em $70,6 \%$ no caso de doentes diagnosticados com «septicémia» e em $86,7 \%$ para doentes diagnosticados com «broncopneumonia».

Tabela 5. Distribuição dos doentes de acordo com o resultado do tratamento*

\begin{tabular}{lrr}
\hline Resultado do tratamento & $\begin{array}{r}\text { No de } \\
\text { doentes }\end{array}$ & $\%$ \\
\hline Alta a pedido da família & 5 & $0,75 \%$ \\
\hline Curado & 527 & $78,66 \%$ \\
\hline Faleceu & 85 & $12,69 \%$ \\
\hline Mesmo estado & 19 & $2,84 \%$ \\
\hline Pediu alta & 8 & $1,19 \%$ \\
\hline Piorado & 25 & $3,73 \%$ \\
\hline Recusou continuar o tratamento & 1 & $0,15 \%$ \\
\hline Total & 670 & $100,00 \%$ \\
\hline
\end{tabular}

* Dados retirados de papeletas de doentes internados nos Hospitais da Universidade de Coimbra. As papeletas encontram-se no Arquivo da Universidade de Coimbra, 40 Piso, 3a Secção, Fundo Universitário. Foram consultadas as caixas no 254 - no 277 , referentes a doentes internados nos Hospitais da Universidade de Coimbra e a quem foi dada alta entre Setembro de 1944 a final de Agosto de 1946.

Ao analisarmos a Tabela 6 constatamos que a penicilina foi prescrita a doentes de todas as faixas etárias, o número de doentes tratados com o medicamento foi relativamente homogéneo em todas as faixas etárias até aos 45 anos de idade. Nas faixas etárias seguintes nota-se um decréscimo progressivo no número de doentes tratados, este fato está em concordância com a esperança média de vida à nascença que em 1940 era de 47,8 anos para os homens e 51,8 anos para as mulheres (Cónim, 1999). Como já havíamos constatado por observação da Tabela 1 «Distribuição dos doentes em função do género", $57 \%$ da penicilina prescrita nos Hospitais da Universidade de Coimbra foi administrada a doentes do sexo masculino e $43 \%$ a 
doentes do sexo feminino, os dados apresentados na Tabela 6 demonstram que as maiores discrepâncias existentes na prescrição de penicilina entre géneros são referentes às faixas etárias do 6 aos 10 anos, dos 16 aos 20 anos, dos 41 aos 45 anos e dos 51 aos 55 anos, a faixa etária dos 26 aos 30 anos é a única, com algum relevo, em que esta situação se inverte.

\section{A APLICAÇÃO CLÍNICA DA PENICILINA: DIAGNÓSTI- COS E POSOLOGIAS}

Outro parâmetro analisado nos doentes admitidos e tratados com penicilina nos Hospitais da Universidade de Coimbra entre Setembro de 1944 e Agosto de 1946 foi o diagnóstico da doença. Na Tabela 7 consta um resumo das patologias nas quais foi prescrita a penicilina. Nesta tabela fazemos referência às enfermidades com maior representatividade, tendo as restantes sido agrupadas na rúbrica denominada "Outros». As patologias respiratórias, nas quais englobámos pneumonias, broncopneumonias, abcessos pulmonares e pleuresias, surgem como a primeira causa de prescrição de penicilina, seguindo-se a osteomielite e depois o fleimão. Estas patologias são tidas como «Indicações absolutas» para a prescrição de penicilina no relatório elaborado por Chester S. Keefer, presidente do Committee on Chemotherapeutic and Other Agents, Division of Medical Sciences, National Research Council, que foi traduzido e publicado na revista Notícias Farmacêuticas com o título «Penicilina: indicações, contraindicações, modo de administração e posologia da penicilina» (Anónimo, 1944) e na revista Jornal do Médico inserido no artigo «Penicilina em Portugal» (Anónimo, 1944). Neste trabalho estão descritas as normas divulgadas por Chester S. Keefer sobre as indicações terapêuticas e as vias de administração da penicilina que

Tabela 6. Distribuição dos doentes de acordo com o sexo e com a idade*

\begin{tabular}{|c|c|c|c|c|c|c|}
\hline Idade & Sexo feminino & $\%$ & Sexo masculino & $\%$ & $\begin{array}{c}\text { № total de } \\
\text { doentes }\end{array}$ & $\%$ \\
\hline $0-5$ & 31 & $4,63 \%$ & 31 & $4,63 \%$ & 62 & $9,25 \%$ \\
\hline $6-10$ & 14 & $2,09 \%$ & 23 & $3,43 \%$ & 37 & $5,52 \%$ \\
\hline $11-15$ & 25 & $3,73 \%$ & 28 & $4,18 \%$ & 53 & $7,91 \%$ \\
\hline $16-20$ & 22 & $3,28 \%$ & 38 & $5,67 \%$ & 60 & $8,96 \%$ \\
\hline $21-25$ & 31 & $4,63 \%$ & 32 & $4,78 \%$ & 63 & $9,40 \%$ \\
\hline $26-30$ & 33 & $4,93 \%$ & 25 & $3,73 \%$ & 58 & $8,66 \%$ \\
\hline $31-35$ & 29 & $4,33 \%$ & 44 & $6,57 \%$ & 73 & $10,90 \%$ \\
\hline $36-40$ & 38 & $5,67 \%$ & 41 & $6,12 \%$ & 79 & $11,79 \%$ \\
\hline $41-45$ & 18 & $2,69 \%$ & 32 & $4,78 \%$ & 50 & $7,46 \%$ \\
\hline $46-50$ & 14 & $2,09 \%$ & 19 & $2,84 \%$ & 33 & $4,93 \%$ \\
\hline $51-55$ & 9 & $1,34 \%$ & 26 & $3,88 \%$ & 35 & $5,22 \%$ \\
\hline $56-60$ & 11 & $1,64 \%$ & 16 & $2,39 \%$ & 27 & $4,03 \%$ \\
\hline $61-65$ & 5 & $0,75 \%$ & 13 & $1,94 \%$ & 18 & $2,69 \%$ \\
\hline $66-70$ & 2 & $0,30 \%$ & 5 & $0,75 \%$ & 7 & $1,04 \%$ \\
\hline $71-75$ & 3 & $0,45 \%$ & 7 & $1,04 \%$ & 10 & $1,49 \%$ \\
\hline $76-80$ & 2 & $0,30 \%$ & 1 & $0,15 \%$ & 3 & $0,45 \%$ \\
\hline $80-85$ & 1 & $0,15 \%$ & & $0,00 \%$ & 1 & $0,15 \%$ \\
\hline$?$ & & $0,00 \%$ & 1 & $0,15 \%$ & 1 & $0,15 \%$ \\
\hline Total/\% & 288 & $42,99 \%$ & 382 & $57,01 \%$ & 670 & $100,00 \%$ \\
\hline
\end{tabular}

* Dados retirados de papeletas de doentes internados nos Hospitais da Universidade de Coimbra. As papeletas encontram-se no Arquivo da Universidade de Coimbra, 4ㅇ Piso, 3ạ Secção, Fundo Universitário. Foram consultadas as caixas no 254 - no 277, referentes a doentes internados nos Hospitais da Universidade de Coimbra e a quem foi dada alta entre Setembro de 1944 a final de Agosto de 1946. 
foram redigidas com base no resultado de um estudo com 3000 casos clínicos abrangendo vários centros de investigação. O estudo teve o apoio do National Research Council (Conselho Nacional de Investigação) e Office of Scientific Research and Development (Repartição de Investigação e Progresso Científico), instituições científicas governamentais norte americanas às quais Chester $\mathrm{S}$. Keefer pertencia. O relatório apresenta quatro grupos de infeções bacterianas organizados de acordo com a sua sensibilidade à penicilina, o primeiro grupo refere as enfermidades em que o tratamento com penicilina deverá constituir uma indicação absoluta, o segundo grupo em que o tratamento com penicilina é uma indicação relativa, o terceiro grupo em que estão incluídos os casos em que a penicilina é de uso discutível e o último grupo em que estão incluídos os casos em que a utilização de penicilina é contra indicada. $\mathrm{O}$ artigo refere os métodos de preparação da penicilina para aplicação terapêutica e as vias de administração do medicamento (intravenosa, intramuscular e tópica), referindo resumidamente as vantagens e desvantagens de cada uma delas. São também apresentadas as doses de referência para os diferentes tratamentos com penicilina, estando estas agrupadas em 5 categorias, sendo referido em cada uma delas a via de administração preferencial. No final do artigo é recomendado aos clínicos que utilizem a penicilina respeitando as indicações fornecidas de modo a «colher o máximo benefício» do "limitado fornecimento de penicilina» (Anónimo, 1944). A informação veiculada no artigo é de extrema importância visto que fornece aos clínicos informações sobre o modo como utilizar a penicilina com máxima eficácia evitando desperdícios decorrentes do seu emprego em enfermidades para as quais não está indicada. Tendo em consideração que a penicilina constituía uma novidade no campo terapêutico entendemos que a divulgação deste relatório, com informação clara e direta, contribuiu para elucidar médicos e farmacêuticos sobre as propriedades e as vantagens da utilização do medicamento.

As septicémias e as infeções ginecológicas ${ }^{30}$, nas quais incluímos a infeção puerperal, também se encontram entre as principais enfermidades com prescrição de penicilina. Nas papeletas consultadas verificámos que a penicilina foi prescrita de acordo com as indicações sugeridas no relatório de Chester Keefer ${ }^{31}$ (Anónimo, 1944), a única exceção que encontramos refere-se à administração do antibiótico a doentes diagnosticados com febre tifoide, nestes casos, de acordo com o relatório do clínico norte-americano, a utilização de penicilina está contra indicada por ser considerada ineficaz.
Tabela 7. Distribuição dos doentes em função do diagnóstico*

\begin{tabular}{lcc}
\hline Diagnóstico & № de Doentes & $\%$ \\
\hline Apendicite & 27 & $4,03 \%$ \\
\hline Difteria & 6 & $0,90 \%$ \\
\hline Doenças venéreas & 4 & $0,60 \%$ \\
\hline Febre tifoide & 10 & $1,49 \%$ \\
\hline Feridas & 7 & $1,04 \%$ \\
\hline Fleimão & 38 & $5,67 \%$ \\
\hline Fraturas & 25 & $3,73 \%$ \\
\hline Furúnculo & 4 & $0,60 \%$ \\
\hline Gangrena & 5 & $0,75 \%$ \\
\hline Ginecologia & 37 & $5,52 \%$ \\
\hline Hérnias & 12 & $1,79 \%$ \\
\hline llegível & 17 & $2,54 \%$ \\
\hline Mastoidite & 12 & $1,79 \%$ \\
\hline Meningite & 16 & $2,39 \%$ \\
\hline Osteomielite & 53 & $7,91 \%$ \\
\hline Patologias respiratórias & 106 & $15,82 \%$ \\
\hline Peritonite & 10 & $1,49 \%$ \\
\hline Pústula maligna & 7 & $1,04 \%$ \\
\hline Queimaduras & 5 & $0,75 \%$ \\
\hline Quisto & 5 & $0,75 \%$ \\
\hline Septicémia & 12 & $5,07 \%$ \\
\hline Síndroma febril & 670 & $100,0 \%$ \\
\hline Sinusite & & $0,6 \%$ \\
\hline Úlcera & $1,79 \%$ \\
\hline Outras & $4,18 \%$ \\
\hline Total & $27,76 \%$ \\
\hline & 54 & \\
\hline
\end{tabular}

* Dados retirados de papeletas de doentes internados nos Hospitais da Universidade de Coimbra. As papeletas encontram-se no Arquivo da Universidade de Coimbra, 4ㅇ Piso, 3a Secção, Fundo Universitário. Foram consultadas as caixas nㅇ $254-$ nㅇ 277, referentes a doentes internados nos Hospitais da Universidade de Coimbra e a quem foi dada alta entre Setembro de 1944 a final de Agosto de 1946

A penicilina surge como medicamento utilizado no tratamento de 670 doentes admitidos nos Hospitais da Universidade durante o período em análise, e em 182 destes casos o medicamento foi prescrito em associação com sulfamidas. As sulfamidas são mencionadas nas papeletas pelo seu nome genérico «sulfamidas»e "sulfatiazol» ou encontram-se prescritas pela denominação comercial «cibazol». Nas formas farmacêuticas utilizadas encontram-se as "empolas», que supomos destinarem-se à administração parentérica, e os com- 
primidos, para administração oral. Relativamente às «empolas» não é referida a posologia empregue, somente a dose total administrada que varia de acordo com a patologia diagnosticada, relativamente aos comprimidos a posologia habitualmente empregue é de um comprimido de duas em duas, três em três ou quatro em quatro horas, as doses totais administradas do medicamento nesta forma farmacêutica variam entre os dois comprimidos e os oitenta comprimidos. Quando analisamos as 1999 papeletas em que houve administração de sulfamidas não associadas à penicilina verificamos que $28,1 \%$ da prescrição é referente a doentes aos quais foi realizada uma intervenção cirúrgica resultante de um diagnóstico de apendicite, úlcera gástrica, estenose do piloro ou hérnia, 20,3\% da prescrição surge associada ao disgnóstico de patologias ginecológicas e obstétricas, em $10,9 \%$ de casos foram prescritas para o tratamento de feridas, abcessos, fleimões e erisipelas e em $7,5 \%$ de casos foram prescritas no tratamento de patologias respiratórias. Verificamos que nos casos em que as sulfamidas foram prescritas associadas a intervenções cirúrgicas a via parentérica, forma farmacêutica «empolas», foi a preferencial, e nas patologias ginecológicas e obstétricas o medicamento foi maioritariamente prescrito em comprimidos para administração oral. Os clínicos prescritores também foi um dos parâmetros analisados na consulta das papeletas dos doentes tratados com sulfamidas, em 49,2\% dos casos não nos foi possível apurar o médico responsável pela instituição da terapêutica, este fato deveu-se ao preenchimento incompleto da papeleta ou à ilegibilidade do nome do clínico. Nas papeletas em que conseguimos identificar o médico verificámos que Bissaya Barreto foi responsável por 16,1\% das prescrições de sulfamidas, José Bacalhau por 6,7\% e Nunes da Costa por 3,4\%, os clínicos Albertino Barros, António Matos Beja, Ibérico Nogueira, Maria Flora Vasconcelos, Novais e Sousa e Palmiro Batista foram responsáveis por $8,4 \%$ das prescrições de sulfamidas, as prescrições destes clínicos surgem associadas às especialidades de ginecologia e obstetrícia.

$\mathrm{Na}$ análise que efetuámos às papeletas dos doentes admitidos nos Hospitais da Universidade de Coimbra, entre Setembro de 1944 e Agosto de 1946, tratados com penicilina também foram examinadas as doses totais administradas, a posologia empregue e o tempo de tratamento. As doses totais administradas, conforme esperado, variaram de acordo com o diagnóstico e com a gravidade dos sintomas não sendo possível estipular um padrão. A partir de Julho de 1945 a penicilina começou a ser importada pela indústria farmacêutica e a sua distribuição deixou de estar sobre o con- trolo da CVP ${ }^{32}$. Verificámos que a partir deste período houve aumento da prescrição de penicilina, o que é coincidente com o aumento da sua produção mundial e com a maior facilidade de acesso ao antibiótico. Dos 670 doentes tratados com penicilina só encontrámos referência à posologia em 4,33\% dos casos, ou seja 29 doentes, em 26 destes casos clínicos a penicilina foi administrada de 3 em 3 horas, tendo sido a dose de 10 000 unidades em 4 casos, 15000 unidades em 3 casos, 20000 unidades em 9 casos e de 40000 unidades num caso, nos restantes 9 casos a dose surge referenciada em centímetros cúbicos, tendo sido administrado 1 centímetro cúbico em 2 doentes, 2 centímetros cúbicos em 6 doentes e 3 centímetros cúbicos num doente. Em 3 pacientes a penicilina foi administrada de 4 em 4 horas, tendo sido a dose prescrita 10000 unidades num caso, 15000 unidades noutro e 20000 unidades no terceiro. As posologias prescritas estão em concordância com as recomendações existentes para o tratamento das patologias diagnosticadas (Barata, 1945). Das 670 papeletas examinadas só 3 nos esclareceram sobre a via de administração empregue, em duas é feita referência à via intramuscular e numa à utilização de pomada de penicilina. Supomos que nos restantes doentes a penicilina tenha sido administrada por via parentética, esse pressuposto baseia-se no fato desta via ser a preferencial para o tratamento de patologias graves (Carvalho, 1944), por ser feita referência, nas papeletas analisadas, a «frascos»e «ampolas» de penicilina e por este medicamento ser indicado por via parentérica no tratamento das patologias encontradas (Keefer, 1946).

Outro parâmetro analisado nas papeletas dos doentes admitidos nos Hospitais da Universidade de Coimbra entre Setembro de 1944 e Agosto de 1945 foi a média dos dias de internamento. Verificámos que nos 20896 doentes admitidos, durante este período, a média de dias de internamento foi de 31,3 dias, relativamente aos 670 doentes tratados com penicilina esta média subiu 32,6\% situando-se em 41,5 dias de internamento, nos 1999 doentes tratados com sulfamidas a média foi 39,7 dias de internamento e nos 18 227 doentes admitidos nos Hospitais da Universidade durante o período analisado a média de dias de internamento foi de 30,6 dias. Entendemos que estes dados suportam o conceito que a administração de penicilina estava reservada para casos muito graves, que mesmo após tratamento necessitavam de períodos de convalescença longos. Ao examinarmos mais pormenorizadamente a distribuição dos doentes, tratados com penicilina, em função dos dias de internamento verificamos que $10,6 \%$ dos doentes têm um período 
de internamento inferior a 5 dias e que neste grupo apenas $33,8 \%$ dos doentes se encontravam curados quando obtiveram alta. No extremo oposto temos $10 \%$ de doentes internados por um período superior a 100 dias, mas ao contrário do grupo anterior neste grupo $86,6 \%$ encontravam-se curados quando obtiveram alta. Embora estes resultados possam parecer estranhos somos da opinião que a taxa de insucesso observada no primeiro grupo é devida à gravidade da doença e ao fato da penicilina ser administrada como último recurso, não conseguindo nestes casos reverter o percurso da doença.

\section{CONCLUSÕES}

A consulta e a análise das papeletas dos doentes admitidos nos Hospitais de Universidade de Coimbra entre Setembro de 1944 e Agosto de 1946 permitiunos recolher informações sobre a introdução da penicilina nestes hospitais. Através dos dados examinados concluímos que a penicilina foi bem aceite e rapidamente incorporada no conjunto de medicamentos

\section{NOTAS}

1. O presente estudo resulta do projeto de investigação de doutoramento (bolsa SFRH/BD/62391/2009) concedida pela Fundação para a Ciência e a Tecnologia - FCT. A investigação integra-se no âmbito das atividades do Grupo de História e Sociologia da Ciência e da Tecnologia do Centro de Estudos Interdisciplinares do Século XX da Universidade de Coimbra - CEIS20 (financiado pela FCT por fundos nacionais do MEC - UID/HIS/00460/2013). Agradecemos à FCT o financiamento concedido; à Cruz Vermelha Portuguesa pelas facilidades concedidas para a consulta do seu arquivo histórico; e ao Arquivo da Universidade de Coimbra, pelas facilidades concedidas.

2. Embora o trabalho de Lesch The First Miracle Drugs: How the Sulfa Drugs Transformed Medicine, tenha como âmbito as sulfamidas é relevante verificar que autor encara a penicilina como o ponto de partida para a descoberta de novos antibióticos.

3. (Bud, 2007), (González \& Orero, 2007), (Santesmases, 2010), (Santesmases, 2011), (Romero de Pablos, 2011), (Capocci, 2011), (Bell et al., 2011), (Bueno et al., 2012), (Brown, 2013).

4. Carta enviada à Cruz Vermelha Brasileira em 27 de Março de 1944. Arquivo da Cruz Vermelha Portuguesa em Lisboa, Livro de Correspondência Expedida, 1944, Volume III, número de ordem 1368.

5. Oficialmente a situação de Portugal na Segunda Guerra Mundial (1939-1945) foi uma posição de neutralidade. Pese embora esta neutralidade, Portugal tornou-se num país com uma forte atividade de espionagem e simultanea- habitualmente prescritos nestes hospitais. Apesar das dificuldades inicialmente existentes na obtenção de penicilina os clínicos dos Hospitais da Universidade de Coimbra procuraram adquirir o medicamento para o tratamento dos seus doentes. Em carta enviada à Cruz Vermelha Portuguesa em 12 de Dezembro de $1944^{33}$ foi sugerida "a entrega de um contingente regular, àquele hospital» de forma a "evitar atrasos na remessa de "Penicilina" "; não conseguimos apurar se a Cruz Vermelha atendeu este pedido, no entanto através de carta datada de 19 de Janeiro de $1945^{34}$ sabemos que a CVP baixou o custo de cada ampola de penicilina enviada àqueles hospitais de $230 \$ 00$ para $130 \$ 00$. Os Hospitais da Universidade de Coimbra utilizaram a penicilina de acordo com as recomendações existentes, as patologias em que foi empregue encontravamse, maioritariamente, entre as de indicação absoluta para a administração do medicamento. Verificámos que a prescrição do medicamento aumentou com o incremento da produção mundial de penicilina e consequente facilidade na sua obtenção.

mente com uma intensa atividade diplomática. Portugal foi um país fundamental como local de passagem para uma enorme quantidade de fugitivos de guerra; alguns fixaram residência em Portugal, outros rumaram para outros países como seja os Estados Unidos da América. O historiador Luís Reis Torgal refere que após a Segunda Guerra Mundial, o Presidente português António de Oliveira Salazar "embora se tivesse esforçado depois da guerra, por explicar que a neutralidade portuguesa fora uma 'neutralidade colaborante', colaborante com os Aliados - o que na realidade aconteceu depois de 1942-43 - , é evidente a sua compreensão pela questão alemã" Luís Reis Torgal, Estados Novos, Estado Novo. Vol. 1, p. 538. (2009). Sobre este assunto ver também Fernando Rosas et al, Portugal na Segunda Guerra Mundial: contributos para uma reavaliação (1989) e Luís Reis Torgal; Heloísa Paulo (coords.), Estados autoritários e totalitários e suas representações (2008).

6. Sobre a constituição de comissões controladoras para a distribuição de penicilina veja-se "Penicillin: A Wartime Accomplishment", Chemical \& Engineering News (1945); Thérapeutique par la Pénicilline (1947) e Raul Rodriguez Nozal "El despacho de penicilina en la España: de las restricciones y el estraperlo", Revista Panacea - Humanidades, Ciencia y Sanidad. (2015).

7. O volume 66 , $\mathrm{n}$ - 1, de 2014 da revista Asclepio tem um dossier inteiramente dedicado ao 150 aniversário da Cruz Vermelha. Veja-se: "War, empire, science, progress, humanitarianism. Debate and practice within the international Red Cross movement from 1863 to the interwar period" com introdução de Jon Arrizabalaga; Guillermo Sánchez -Martínez; Jon Arrizabalaga e Guillermo Sánchez-Martínez, 
Leo van Bergen; e Francisco Javier Martínez-Antonio. Nestes estudos fica bem clara a natureza assistencial da Cruz Vermelha que era necessariamente a vocação da Cruz Vermelha Portuguesa.

8. No livro de atas da Junta Consultiva, localizado no Arquivo da Cruz Vermelha Portuguesa, é-lhe atribuído o nome de Junta Consultiva da Cruz Vermelha Portuguesa para a Distribuição de Penicilina em Portugal, no entanto em correspondência diversa é referida como Junta Consultiva para a Distribuição de Penicilina em Portugal ou Junta Consultiva de Distribuição de Penicilina em Portugal. Para evitar equívocos e de forma a simplificar a leitura futuramente iremos referir-nos a esta comissão como JCDPP.

9. Francisco Gentil (1878-1964) foi um dos mais prestigiados médicos portugueses do seu tempo. Foi cirurgião e professor da Faculdade de Medicina da Universidade de Lisboa, da qual foi diretor. Com forte influência nos meios sociais e políticos da época, Francisco Gentil sendo o principal impulsionador do Instituto Português de Oncologia, fundado em 1923 com o nome de Instituto Português para o Estudo do Cancro. O Instituto Português tem o nome de Francisco Gentil.

10. Fernando da Fonseca (1895-1974) foi professor da Faculdade de Medicina da Universidade de Lisboa, sendo professor de Propedêutica Médica, e médico dos Hospitais Civis de Lisboa. Exerceu uma conhecida atividade clínica e deixou um conjunto vasto de publicações científicas. Estagiou nos Estados Unidos da América na área da oncologia. Exerceu, também, significativa atividade cívica criticando por vezes a atuação do Governo em matérias de assistência na doença, como aconteceu em 1947 numa reunião do Movimento da Unidade Democrática, movimento político de oposição ao governo de Salazar, ilegalizado em 1948. O Hospital Amadora Sintra tem o nome de Fernando Fonseca.

11. João Maia Loureiro (1901-1948) foi professor da Faculdade de Medicina de Lisboa tendo exercido clínica nos Hospitais Civis de Lisboa e no Instituto Português de Oncologia. Esteve por diversas vezes no estrangeiro a realizar estágios em diversas áreas da medicina. Dedicou-se com particular destaque no campo da saúde pública e da epidemiologia e às análises clínicas tendo sido entre outros cargos chefe de serviço e médico analista dos Hospitais Civis de Lisboa e diretor do Instituto Bacteriológico Câmara Pestana (Lisboa).

12. Ernesto Galeão Roma (1887-1978) foi um prestigiado médico português que teve particular interesse pela diabetes. Esteve nos Estados Unidos da América onde presenciou algumas das primeiras aplicações de insulina. Em Portugal, além da atividade clínica fundou em 1926 a Associação Protetora dos Diabéticos Pobres mais tarde designada por Associação Protetora dos Diabéticos de Portugal (APDP) e que depois de transformou em Fundação Ernesto Roma - APDP, uma instituição pioneira a este nível no plano mundial.

13. Parece-nos oportuno transcrever a nota de imprensa fornecida pelo Ministério da Economia: “Em virtude de estarem a chegar ao País, com certa regularidade as remessas de penicilina, entende a Comissão Reguladora dos Produtos Químicos e Farmacêuticos, de acordo com a Direcção Geral de Saúde Pública, ser desnecessário continuar a observar as medidas em devido tempo tomadas sobre a venda deste medicamento, pelo que as mesmas são eliminadas a partir desta data, excepto no que respeita à sua aplicação, que só poderá fazer-se, como até aqui, sob prescrição e responsabilidade médica", Jornal do Médico (1945) e Eco Farmacêutico (1945).

14. Hospitais da Universidade de Coimbra era a designação dada a uma unidade hospitalar que se encontrava dividida por alguns edifícios na cidade de Coimbra. Na verdade, pode dizer-se que a designação de Hospitais da Universidade de Coimbra era dada ao hospital da Universidade de Coimbra, hospital aberto à população e que servia como hospital escolar. A sua origem remonta ao século XVIII quando com a reforma da Universidade de 1772 se entendeu que a Universidade de Coimbra deveria ter um hospital escolar. Foram reunidos num só hospital e em edifício próprio os três antigos hospitais da cidade: o Hospital da Convalescença, o Hospital da Conceição e o Hospital de S. Lázaro. Sobre este assunto veja-se João Rui Pita, Farmácia, medicina e saúde pública em Portugal (1772-1836), pp. 270-284, (1996).

15. As papeletas de doentes internados nos Hospitais da Universidade de Coimbra encontram-se no Arquivo da Univer-

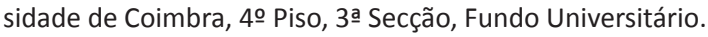
Foram consultadas as caixas no 254 - no 277, referentes a doentes internados nos Hospitais da Universidade de Coimbra e a quem foi dada alta entre Setembro de 1944 a final de Agosto de 1946, tendo sido analisadas 20898 papeletas.

16. No Arquivo da Universidade de Coimbra (que é um arquivo histórico) encontra-se o espólio dos hospitais da cidade de Coimbra desde o século XVII. Neste arquivo encontramos documentação variada sobre o Hospital da Universidade de Coimbra e entre esta documentação os processos clínicos dos doentes (designados por papeletas). Nestes processos temos informação variada sobre o doente, o diagnóstico e a terapêutica que foi estabelecida. Também há a assinatura do médico. Contudo, nem sempre todos os processos estão preenchidos na sua totalidade. Por vezes há alguns que estão incompletos. A investigação em processos clínicos permite avaliar, entre outros elementos, o que era receitado na prática aos doentes internados. Trata-se de um valioso espólio documental muito importante para a história da farmácia mas também, entre outras áreas da medicina, muito importante para a história da terapêutica (neste caso medicamentosa).

17. As sulfamidas (cuja atividade antibacteriana foi descrita em 1935 por Gerhard Domagk) desempenharam um importante papel no desenvolvimento da terapia antimicrobiana mas a sua toxicidade e o aparecimento de fenómenos de resistência bacteriana condicionaram a sua utilização, o surgimento da penicilina com a sua quase ausência de toxicidade aliada a um forte ação antibacteriana tornaram- 
na no medicamento de primeira indicação no tratamento de infeções bacterianas. Com a introdução da penicilina na terapêutica (nos anos 40 do século XX) a utilização das sulfamidas diminuiu substancialmente. Da análise dos dados recolhidos das papeletas dos Hospitais da Universidade de Coimbra, para o período analisado, verificámos que houve uma prescrição superior de sulfamidas relativamente à penicilina. Este facto não é de estranhar visto a utilização das sulfamidas anteceder, em alguns anos, a utilização da penicilina e o custo associado ao seu tratamento ser substancialmente inferior ao da penicilina. Excluindo os casos em que a utilização da penicilina era considerada de indicação absoluta, o antibiótico encontrava-se reservado para casos graves e de resistência comprovada às sulfamidas.

18. Telegrama do Dr. João Porto, Diretor dos Hospitais da Universidade de Coimbra, de 05 de Dezembro de 1944. Arquivo da Cruz Vermelha Portuguesa em Lisboa, Livro de Correspondência Recebida, 1944, número de ordem de entrada 5714

19. Telegrama do Dr. João Porto, Diretor dos Hospitais da Universidade de Coimbra, de 08 de Dezembro de 1944. Arquivo da Cruz Vermelha Portuguesa em Lisboa, Livro de Correspondência Recebida, 1944, número de ordem de entrada 5812.

20. A ausência de preservação dos arquivos de instituições de saúde portuguesas como hospitais, centros de saúde constitui um grave problema para a investigação em história da medicina, da farmácia ou de outra área das ciências e das profissões de saúde. Constatamos como já foi referido por investigadores espanhóis e para o caso de Espanha, que também em Portugal tem havido imensas perdas do património documental histórico-médico e histórico-farmacêutico. Nos últimos anos encerraram em Portugal diversos hospitais com espólio documental de grande valor e a preservação desse espólio, do nosso ponto de vista, não está a ser feita ou, na sua generalidade, pode não ser feita do melhor modo. No Arquivo da Universidade de Coimbra o património documental dos Hospitais da Universidade de Coimbra está preservado e catalogado até meados do século XX o que permite a realização de estudos históricosanitários. Também encontrámos em bom estado de conservação e de catalogação o Arquivo da Cruz Vermelha Portuguesa, em Lisboa, embora o património documental existente corresponda apenas a uma parte do espólio que já existiu. Também em instituições privadas encontramos em Portugal o mesmo problema de dificuldades de consulta ou de destruição de arquivos. Partilhamos, por isso, das preocupações e das sugestões feitas, por exemplo, por Esteban Rodriguez Ocaña (1976) “Archivos administrativos contemporâneos" Dynamis, 9, pp. 79-90. Vejam-se, também, na mesma revista outros estudos publicados no dossier "Actas del III Simposio de la Sociedad Espanola de Historia de la Medicina. La defensa del patrimonio documental históricomédico español", Dynamis, 9, 1989, pp. 11-115

21. As sulfamidas são mencionadas nas papeletas dos doentes admitidos nos Hospitais da Universidade pelo seu nome ge- nérico "sulfamidas" e "sulfatiazol" ou encontram-se prescritas pela denominação comercial "cibazol".

22. Papeleta de doente internado nos Hospitais da Universidade de Coimbra número 4537. Arquivo da Universidade de Coimbra, 4o Piso, 3a Secção, Fundo Universitário, caixa $\mathrm{n}$ ㅇ 256 .

23. Através da consulta do documento: Comunicações à Comissão Central da Cruz Vermelha Portuguesa apresentadas na sessão de 18 de Outubro de 1944. Arquivo da Cruz Vermelha Portuguesa em Lisboa, Livro de atas da Comissão Central da Cruz Vermelha Portuguesa, 1944. Ficamos conhecedores do preço previsto (200\$00), pela Cruz VermeIha Portuguesa, para o custo de cada ampola de 100000 unidades de penicilina. No entanto quando consultámos o documento: Recibo emitido à Companhia Rádio Marconi a 18 de Dezembro de 1944. Arquivo da Cruz Vermelha Portuguesa. Cruz Vermelha Portuguesa - Junta Consultiva de Distribuição de Penicilina em Portugal, Volume I, 1944 - 1945. Constatamos que na realidade cada ampola de 100000 unidades de penicilina custava $230 \$ 00$ e não $200 \$ 00$ como foi inicialmente previsto. Em 1945, quando se iniciou a importação através da indústria farmacêutica, cada ampola de 500000 unidades de penicilina custava 210\$00 (cada 100000 unidades custariam 42\$00), veja-se, Comissão Reguladora dos Produtos Químicos e Farmacêuticos (1956) Medicamentos especializada e produtos químicos medicinais - Volume II, Lisboa, Gráfica Boa Nova Ld.a , pp. 188-189.

24. Com o aumento da produção mundial de penicilina deixou de ser necessária a intervenção de comissões controladoras na sua distribuição e o seu custo diminuiu substancialmente. Conforme já tivemos oportunidade de referir quando a penicilina começou a ser importada e distribuída pela CVP o custo de 100000 unidades do antibiótico era de $230 \$ 00$. A partir de 1945 , conforme foi referido anteriormente, o preço de venda ao público da penicilina diminuiu substancialmente. Podemos constatar este facto através do artigo "Dois assuntos" e do anúncio "Penicilina" publicados na revista Eco Farmacêutico, assim como através da obra Medicamentos especializada e produtos químicos medicinais - Volume II, Lisboa, Gráfica Boa Nova Ld.a , pp. 188-189.

25. Circular do Grémio Nacional da Farmácias enviada à Farmácia Cruz Viegas a 13 de Julho de 1945. Centro de Documentação Farmacêutica da Ordem dos Farmacêuticos - Delegação Regional de Coimbra, Coimbra.

26. Fernando Baeta Bissaya Barreto Rosa (1886-1974), mais conhecido por Bissaya Barreto, formou-se em medicina na Faculdade de Medicina da Universidade de Coimbra em 1911. Foi nomeado, no mesmo ano, Assistente Provisório e em 1916, Diretor da Clínica Terapêutica e Técnica Operatória dos Hospitais da Universidade de Coimbra. Figura política relevante do Estado Novo (aderiu à União Nacional após a revolução de 28 de Maio de 1926 que havia de dar lugar à subida de Salazar ao poder) teve papel significativo em Portugal ao projetar obras de natureza social e hospitalares no distrito de Coimbra e na região centro de Portugal. Exerceu 
um importante contributo para a consagração do direito à Assistência Social na Constituição da República Portuguesa de 1911. Em 1930 fundou o Ninho dos Pequenitos, uma instituição dedicada à assistência infantil e onde o bem-estar da criança, em todas as suas vertentes, era uma prioridade. Enquanto Presidente da Junta Geral do Distrito de Coimbra (1927-1974) inaugurou em 1940 o Portugal dos Pequenitos e na dependência desta a Casa da Criança Rainha Santa Isabel e em 1958 criou a Fundação Bissaya Barreto dedicada a dar continuidade à sua obra de assistência social. Sobre este médico veja-se, por exemplo, Jorge Pais de Sousa (1999), Bissaya Barreto: ordem e progresso, Carolina G. M. Álvaro (2011), Ternura e sensibilidade : os primeiros anos do Ninho dos Pequenitos de Coimbra (1930-1939) e o seu processo de professor no Arquivo da Universidade de Coimbra: DIV-S1ㅁD-E6-T1.

27. Luís Augusto de Morais Zamith (1897-1983) doutorou-se em medicina pela Faculdade de Medicina da Universidade de Coimbra em 1920. Exerceu vários cargos nos Hospitais da Universidade. Em 1950 foi eleito Presidente da Sociedade Portuguesa de Urologia, especialidade onde realizou clínica e importantes trabalhos de investigação. Realizou pesquisas sobre o tratamento de doenças venéreas. Em colaboração com Ângelo da Fonseca (1872-1942) publicou estudos sobre a utilização da anestesia epidural, trabalhos pioneiros no emprego desta anestesia nos Hospitais da Universidade de Coimbra. Veja-se o seu processo de professor no Arquivo da Universidade de Coimbra: DIV-S1äD-E9-T3 e também o estudo $A$ anestesia nos séculos XIX XX e os Hospitais da Universidade de Coimbra (2008).

28. João Maria Porto (1891-1968), doutorou-se em medicina pela Faculdade de Medicina da Universidade de Coimbra, em 1920. Figura muito ligada aos meios católicos, foi Presidente da Associação de Médicos Católicos Portugueses. Foi Diretor de Clínica Pediátrica, Diretor de Clínica de Moléstias Infeciosas (1941), Diretor da Faculdade de Medicina (19361941), Diretor dos Hospitais da Universidade (1942-1950), interessou-se muito pela cardiologia, tendo-se notabilizado no campo da medicina interna. Foi Diretor da revista Coimbra Médica entre 1934 e 1948. Fundou o Centro MédicoSocial de Coimbra em 1940 e em 1944 criou o Centro de Investigações Dermatológicas e de Transfusão de Sangue. Veja-se o seu processo de professor no Arquivo da Universidade de Coimbra: DIV-S1äD-E7-T5.

29. Não é possível fazer a relação entre o prestígio do médico e a capacidade de atração de doentes por parte daquele. No entanto, os Hospitais da Universidade de Coimbra eram uma referência nacional. No centro de Portugal e captavam os doentes das regiões circundantes de Coimbra.

30. Não foram neste caso incluídas as doenças sexualmente transmissíveis, como sífilis, visto estas doenças serem de "indicação relativa", para a administração do antibiótico ficando a penicilina reservada para as doenças de "indicação absoluta" (expressões utilizadas no relatório de Chester S. Keefer).

31. Chester Scott Keefer (1897 - 1972), medico, durante a II Guerra Mundial foi nomeado presidente do National Research Council's Committee on Chemotherapeutics and Other Agents, sendo responsável pela distribuição de penicilina nos EUA.

32. Em Junho de 1945, com o aumento da produção mundial, as quantidades de penicilina disponíveis já eram suficientemente elevadas para que o antibiótico pudesse ser vendido sem restrições. A intervenção de comissões controladoras na sua distribuição deixou de ser necessária e a 12 de Junho de 1945 a Junta Consultiva da Distribuição da Penicilina em Portugal foi extinta. Veja-se: Carta enviada à Junta Consultiva para a Distribuição da Penicilina em Portugal em 12 de Junho 1945. Arquivo da Cruz Vermelha Portuguesa. Cruz Vermelha Portuguesa - Junta Consultiva de Distribuição de Penicilina em Portugal, Volume I, 1944 - 1945. A penicilina começou então a ser importada como medicamento. Por deliberação da Comissão Reguladora dos Produtos Químicos e Farmacêuticos (entidade reguladora do setor farmacêutico), o antibiótico só poderia ser vendido em farmácias mediante a apresentação obrigatória de uma prescrição. Alguns dos primeiros laboratórios importadores e distribuidores foram o Instituto Pasteur de Lisboa, a Farmácia Barral e o Laboratório Sanitas com delegações em Lisboa, Porto e Coimbra e a Sociedade Industrial Farmacêutica e Santos Mendonça Ld.a em Lisboa. Em 1947, a penicilina começou a ser importada como matéria-prima e em 1948, após a instalação da primeira câmara asséptica, foram introduzidos no mercado português as primeiras especialidades farmacêuticas com penicilina manipuladas em Portugal (Penicilina - sal sódico ou potássico, Procaína penicilina com penicilina cristalizada). Só mais tarde, em 1966 surgiu a primeira fábrica de penicilina do país, em Matosinhos - Sociedade Produtora de Leveduras Seleccionadas e Micofabril, a primeira fazendo a biossíntese, extração e refinação da penicilina enquanto a segunda transformava a matéria-prima em especialidades farmacêuticas, embalando-as e lançando-as no mercado.

33. Carta dos Hospitais da Universidade de Coimbra, de 12 de Dezembro de 1944. Arquivo da Cruz Vermelha Portuguesa em Lisboa, Livro de Correspondência Recebida, 1944, número de ordem de entrada 5904

34. Carta enviada para os Hospitais da Universidade de Coimbra, em 19 de Janeiro de 1945. Arquivo da Cruz Vermelha Portuguesa em Lisboa, Livro de Correspondência Expedida, 1945, Volume I, número de ordem 323. 


\section{BIBLIOGRAFIA}

Álvaro, C. G. M. (2011), “Ternura e sensibilidade : os primeiros anos do Ninho dos Pequenitos de Coimbra (1930-1939)", Tese de Mestrado. Faculdade de Letras da Universidade de Coimbra.

Anónimo (1944), "Penicilina em Portugal”, Jornal do Médico, 4 (93), p. 709.

Anónimo (1944), "Penicilina: indicações, contra-indicações, modo de administração e posologia da penicilina", Notícias Farmacêuticas, XI (3-4), pp. 160-164.

Anónimo (1945), "Cessaram as restrições na venda da Penicilina", Eco Farmacêutico, 7 (91), p. 19.

Anónimo (1945), “Dois assuntos”, Eco Farmacêutico, 7 (58), p. 1.

Anónimo (1945), "Penicilina”, Eco Farmacêutico, 7 (59), p. 8

Anónimo (1945), "Penicillin: A Wartime Accomplishment", Chemical \& Engineering News, 23 (24), pp. 2310-2316

Anónimo (1945), "Regulamento da venda da Penicilina", Eco Farmacêutico, 7 (58), p. 8.

Anónimo (1949), "João Avelar Maia de Loureiro [biobibliografia] ", Gazeta Médica Portuguesa, 2 (4), pp. 959-964.

Azevedo, J. Fraga de (1976), “A importante escola prática dos Hospitais Civis de Lisboa. A personalidade do Prof. Fernando Fonseca" O Médico. Nova série, 78 (1270), pp. 21-23.

Barata, P. (1945), "Penicilina - Revista geral”, Jornal do Médico, VI (132), pp. 313-321, p. 316.

Bell, V. (2015), "Introdução dos antibióticos em Portugal: ciência, técnica e sociedade (anos 40 a 60 do século XX). Estudo de caso da penicilina", Tese de Doutoramento. Faculdade de Farmácia da Universidade de Coimbra.

Bell, V.; Pita, J. R. e Pereira, A. L. (2011), “A importância do Brasil no fornecimento das primeiras doses de penicilina para Portugal (1944)". En: Fiolhais, C.; Simões, C.; Martins, D. (eds.), Congresso Luso-Brasileiro de História das Ciências. Coimbra, pp. 878-891.

Bessa, José dos Santos (1986), "A obra médico-social do Doutor Bissaya-Barreto", Revista da Fundação Bissaya-Barreto, $1(1)$, pp. 9-13.

Brown, Kevin (2013), Penicillin man. Alexander Fleming and the antibiotic revolution. Gloucestershire, The History Press.

Bud, Robert (2007), Penicillin Triumph and Tragedy. Oxford University Press.

Capocci, M. (2011), "'A Chain is gonna come'. Building a penicillin production plant in post-war Italy", Dynamis, 31 (2), pp. 343-362.
Carvalho, R. de (1944), "Penicilina: seu estudo entre 1929 e 1943", Jornal dos Farmacêuticos, III (31 a 32), pp. 95-129, p. 108-111.

Clímaco, R. (1946), "Revisão clínica das psicoses infecciosas e pós infecciosas", A Medicina Contemporânea, 64( 6), pp. 215-253.

Comissão Reguladora dos Produtos Químicos e Farmacêuticos (1956), Medicamentos especializada e produtos químicos medicinais - Volume II. Lisboa, Gráfica Boa Nova Ld.a , pp. 188-189

Cónim, C. N. P. da S. (1999), Geografia do envelhecimento da população portuguesa - Aspetos Sociodemográficos 19702021, Departamento de Prospetiva e Planeamento. Lisboa, SCARPA, p. 11.

Couto, Alberto (1983), "Um vianense insigne: o Doutor Ernesto Galeão Roma”, Cadernos Vianenses, 7, pp. 22-26.

Florey, M. E. (1944), “Utilização terapêutica da penicilina”, Clínica, Higiene e Hidrologia, X (4), pp. 106-112, p. 107.

González Bueno, A.; Rodríguez Nozal, R. e Teijón, C. J. P. (2012), "La penicilina en Espanã: difusión, propriedad industrial y negocio, en clave autárquica (1944-1959)", Estudos do Século XX, (12), pp. 271-287.

González, J., Orero, A. (2007), “Historia La penicilina Ilega a España: 10 de marzo de 1944, una fecha histórica", Revista Española Quimioterapia, 20 (4), pp. 446-450.

Hospitais da Universidade de Coimbra (1947), "Movimento clínico do ano de 1941 - Estatística geral das doenças", Boletim dos Hospitais da Universidade de Coimbra, X, pp. 24-37.

Keefer, C. S. (1946), "Formas farmacológicas, doses e indicações da penicilina”, Jornal do Médico, VII (161), pp. 394-397.

Leone, José (1978), "No ano do centenário do Prof. Francisco Gentil (A sua passagem pelos Hospitais Civis de Lisboa) ", Boletim Clínico dos Hospitais Civis de Lisboa, 38 (1-4), pp. 257-266.

Lesch, J. E. (2007), The First Miracle Drugs: How the Sulfa Drugs Transformed Medicine. New York, Oxford Univ Press, p. 210.

Ministère de la Santé Publique (1947), Thérapeutique par la Pénicilline, Primiere ed. Paris, Masson et Cie, Éditeurs.

Ministério da Economia (1945), "Venda de penicilina”, Jornal Do Médico, 6 (147), p. 765

Pita, João Rui (1996), Farmácia, medicina e saúde pública em Portugal (1772-1836). Coimbra, Minerva, pp. 270-284.

Queijo, J. (2010), Breakthough - How the 10 greatest discoveries in medicine saved millions and changed our view of the worId. New Jersey, Pearson Education, Inc, p. 142. 
Rodriguez Nozal, Raul (2015), "El despacho de penicilina en la España: de las restricciones y el estraperlo", Revista Panacea - Humanidades, Ciencia y Sanidad, 1 (Janeiro), pp. 14-15.

Rodriguez Ocaña, Esteban (1976), "Archivos administrativos contemporâneos" Dynamis, 9 (Actas del III Simposio de la Sociedad Española de Historia de la Medicina), pp. 79-90.

Romero de Pablos, A. (2011), "Regulation and the circulation of knowledge: penicillin patents in Spain", Dynamis, 31(2), pp. 363-383.

Rosas, Fernando et al. (1989), Portugal na Segunda Guerra Mundial: contributos para uma reavaliação. Lisboa, Dom Quixote.

Santesmases, M. J. (2010), "Distributing Penicillin: the clinic, the hero and industrial production in Spain, 1943-1952". En: Quirke, V.; Slinn, J. (eds.) Perspectives on Twentieth-Century Pharmaceuticals. Oxford, Peter Lang, pp. 91-118.

Santesmases, M. J. (2011), "Screening antibiotics: industrial research by CEPA and Merck in the 1950s", Dynamis, 31 (2), pp. 407-427.
Santos, J. C. dos (1954), "O aviso prévio do Prof. Cid dos Santos", O Médico, 5 (129), pp. 112-118, p. 116.

Serviço de Anestesiologia dos Hospitais da Universidade de Coimbra (2008), A Anestesia nos séculos XIX e XX e os Hospitais da Universidade de Coimbra, $1^{\text {a }}$ edição. Serviço de Anestesiologia dos Hospitais da Universidade de Coimbra (ed.), Coimbra, Impressões e Soluções, p. 32-33.

Sousa, Jorge Pais (1999), Bissaya Barreto: Ordem e Progresso. Coimbra, Minerva.

Torgal, Luís Reis (2009), Estados Novos, Estado Novo. 2 Vols. Coimbra, Imprensa da Universidade, p. 538.

Torgal, Luís Reis; Paulo, Heloísa (coords.) (2008), Estados autoritários e totalitários e suas representações. Coimbra, Imprensa da Universidade de Coimbra.

Waller, J. (2004), Fabulous science: fact and fiction in the history of scientific discovery. Oxford University Press, p. 247. 